\title{
Genetic diversity loss due to selection for scrapie resistance in the rare Spanish Xalda sheep breed
}

\author{
I. Álvarez ${ }^{\text {a }}$, L.J. Royo ${ }^{\text {a }}$, J.P. Gutiérrez ${ }^{\text {b }}$, I. Fernández ${ }^{\text {a }}$, J.J. Arranz ${ }^{\text {c }}$, F. Goyache ${ }^{\text {a,* }}$ \\ a SERIDA-Somió, C/ Camino de los Claveles 604, E-33203 Gijón (Asturias), Spain \\ ${ }^{\mathrm{b}}$ Departamento de Producción Animal, Facultad de Veterinaria, Avda, Puerta de Hierro s/n, E-28040-Madrid, Spain \\ ${ }^{\mathrm{c}}$ Departamento de Producción Animal I, Universidad de León, E-24071 León, Spain
}

Received 1 August 2006; received in revised form 5 January 2007; accepted 15 January 2007

\begin{abstract}
The effect of selection for scrapie resistance on genetic variability in the rare Xalda sheep breed was studied. Pedigree information comprised 1851 animals (1444 alive) at the moment of sampling. A total of 304 reproductive (or selected for reproduction) Xalda individuals were sampled and genotyped for 14 microsatellites. Genetic variability was assessed using: gene diversity (1 - average kinship, GD), mean average relatedness (AR) and self-coancestry $\left(c_{i}\right)$ at the genealogical level; and expected heterozygosity $\left(H_{\mathrm{e}}\right)$, molecular mean kinship $(\mathrm{Mk})$, molecular self-coancestry $\left(s_{i}\right)$ and rarefacted average number of alleles per locus $(A)$ at the molecular level. Two breeding strategies were evaluated: a) use of only young rams with genotype ARR/ARR and young ewes with low to moderate risk (risk groups R1 to R3); b) breeding without selection for PrP genotypes. The major cause of losses of genetic variability in the Xalda breed is the drift that occurs when a new group of reproductive individuals is selected. The loss of genetic variability is small in females compared to the males, where it is considerable. However, losses at the molecular level for young females with respect to adult females were above 5\%. Young male individuals also retained most of the genetic variability assessed in adult rams. Selection against susceptibility to scrapie produced additional losses of more than $2 \%$ for $H_{\mathrm{e}}$ and $A$ when rYF individuals are considered. As regards males, the situation becomes critical because of the scant number of available ARR/ARR young rams. The consequences for the management of the Xalda breed are discussed.
\end{abstract}

(C) 2007 Elsevier B.V. All rights reserved.

Keywords: Genetic variability; Inbreeding; Homozygosity; Coancestry; Conservation program; PrP

\section{Introduction}

Scrapie is one of the diseases of the group of transmissible spongiform encephalopathies, which also includes Creutzfeldt-Jakob disease in humans and bovine spongiphorm encephalopathy (BSE) in cattle (Hunter, 1997; Prusiner, 1998).

\footnotetext{
* Corresponding author. Tel.: +34 985195303; fax: +34 985195310 .

E-mail address: fgoyache@serida.org (F. Goyache).
}

In the light of scientific evidence relating mutation in the codons 136, 154 and 171 of the third exon of the PrP gene to the degree of susceptibility to scrapie in sheep (Hunter, 1997; Elsen et al., 1999; O’Doherty et al., 2002), the European Union has classified the alleles and the genotypes for scrapie in five categories from highly resistant (R1) to highly sensitive (R5) and has decided that breeding programs aimed at decreasing susceptibility to scrapie should be implemented in all the sheep breeds in its territory (European Commission, 2003; see also Gama et al., 2006, for a review). The goals of these programmes 
must include increasing the frequency of the ARR allele and the ARR/ARR homozygous genotype, which are considered highly resistant to scrapie, and the elimination of the VRQ allele, which has been shown to be highly sensitive to clinical scrapie (Hunter, 1997; Elsen et al., 1999; European Commission, 2003). These kinds of breeding programmes are criticised because they unavoidably reduce the available genetic variability in a breed, thus affecting selection and conservation programmes in sheep.

The protection of the genetic base of a population in risk has usually been measured by the rate of inbreeding (Windig et al., 2004). However, the computation of the individual coefficient of inbreeding is highly sensitive to the quality of the available pedigree information, thus making this parameter difficult to interpret (Goyache et al., 2003). Consequently, a number of recent studies (Caballero and Toro, 2000, 2002; Fernández et al., 2005) have used expected heterozygosity (Nei, 1987), usually called gene diversity (GD), as a criterion for quantifying genetic variability. In addition, recent studies (Caballero and Toro, 2002; Eding and Meuwissen, 2001) have formalised the way in which it is possible to obtain coancestry coefficients from molecular information by applying Malécot's (1948) definition to the marker genes, though referring to identity by state instead of identity by descent. Owing to its straightforward relationship with genealogical coancestry, this parameter has been shown to be useful for conservation purposes (Toro et al., 2002, 2003; Royo et al., 2007). From a molecular perspective, another important measure of variability is allelic richness or average number of alleles per locus ( $A$; Hurlbert, 1971; Fernández et al., 2005).

Several studies analysed how selection for scrapie resistance can affect performance traits (Brandsma and Visscher, 2004; De Vries et al., 2005; Vitezica et al., 2005). However, the assessments of the effect of such breeding programmes on the genetic variability in small-rare sheep breeds are scarce and have been only conducted at the genealogical level (Windig et al., 2004). Here, the effect of selection for scrapie resistance on genetic variability in the rare Xalda sheep breed is assessed, using theoretically equivalent parameters at the genealogical and molecular level. The study is done assuming the actual selective policy carried out by the Xalda breeders. The consequences on the management of the Xalda breed will be discussed.

\section{Materials and methods}

\subsection{Flockbook information and risk groups}

The Xalda (Álvarez Sevilla et al., 2004) is an endangered sheep breed mainly located in Asturias
(Northern Spain) that can be included within the Spanish Celtic sheep breeds including Churra and Latxa breeds (Álvarez et al., 2004). During the 1990s, a conservation program commenced with the foundation of a flockbook, the recovery of reproductive individuals in isolated flocks and the implementation of pure breed mating policy (Álvarez Sevilla et al., 2004; Goyache et al., 2003). Apart from preservation, breeders select individuals for reproduction by their accordance to the breed standard (Álvarez Sevilla et al., 2004; Goyache et al., 2003) and a significant number of individuals (especially males) born each lambing season do not remain in the flocks.

The information registered in the Xalda flockbook since its foundation to June 1st 2005 was obtained from the breeders association (ACOXA). The flockbook included a total of 1851 animals (217 males) and more than 100 small sized flocks. The total number of flocks registered in the flockbook is significantly higher than the number of active flocks each year due to the short duration of some of them. Up to 1444 individuals (134 males) were alive at the moment of sampling and a total of 58 flocks were active. Flocks are of small size and usually have only one ram. Though the number of founders is large (325) the pedigree knowledge at population level is high $(79.8 \%$ of the fathers and $55.1 \%$ of the mothers known). No Xalda individual can be traced more than nine generations back in its pedigree. From the living reproductive individuals over 39\% aged between 2 and 3 years old and $43 \%$ aged between 4 and 6 years old. Rams have usually a large reproductive life and are commonly exchanged between flocks. In this respect, over $28 \%$ of the available rams is 7 or more years old.

PrP genotypes, analysed at the Central Veterinary Laboratory of the Spanish Ministry of Agriculture, corresponding to the individuals born in the last lambing season were also provided by ACOXA. Individual genotypes were classified in five risk groups (European Commission, 2003) from R1 (very low) to R5 (greatest risk). A more detailed description of the risk groups can be found in Table 1.

\subsection{Definition of breeding groups and breeding strategies}

In order to define breeding groups for genetic analyses, the living individuals registered in the flockbook were grouped in the following groups according to age and sex: a) adult males (AM); b) adult females (AF); c) young males (YM); and d) young females (YF). The $\mathrm{AM}$ and $\mathrm{AF}$ groups were formed by, respectively, 123 
Table 1

Classification of PrP genotype in risk groups, risk description, genotype frequencies and allelic frequencies for the PrP gene in the selected individuals for reproduction (see text) in the Xalda sheep breed of Asturias, by sex of the individuals (YM — males and YF — females)

\begin{tabular}{|c|c|c|c|c|c|c|}
\hline \multirow[t]{2}{*}{ Genotype } & \multirow{2}{*}{$\begin{array}{l}\text { Risk } \\
\text { group }\end{array}$} & \multicolumn{2}{|l|}{ Risk description } & \multicolumn{3}{|c|}{ Reference group } \\
\hline & & At individual level & At progeny level & YM & YF & Total \\
\hline ARR/ARR & $\mathrm{R} 1$ & Very low & Very low & $2^{a}(18.18)$ & $9^{b}(4.95)$ & $11(5.70)$ \\
\hline ARR/AHQ & $\mathrm{R} 2$ & Low & Low & & $1^{\mathrm{b}}(0.55)$ & $1(0.52)$ \\
\hline \multicolumn{7}{|l|}{ AHQ/AHQ } \\
\hline ARQ/AHQ & R3 & Low & Not low depending on the genotype & & & \\
\hline AHQ/ARH & & & of the other parent & & & \\
\hline ARR/ARH & & & & & $1^{\mathrm{b}}(0.55)$ & $1(0.52)$ \\
\hline ARR/ARQ & & & & $1(9.09)$ & $60^{\mathrm{b}}(32.97)$ & $61(31.61)$ \\
\hline AHQ/VRQ & $\mathrm{R} 4$ & Scrapie occasionally recorded & Higher risk than in R3 progeny & & & \\
\hline ARR/VRQ & & & & & $2(1.1)$ & $2(1.04)$ \\
\hline ARQ/ARQ & & & & $8(72.73)$ & $99(54.4)$ & $107(55.44)$ \\
\hline $\mathrm{ARQ} / \mathrm{ARH}$ & & & & & $7(3.85)$ & $7(3.63)$ \\
\hline \multicolumn{7}{|l|}{ ARH/ARH } \\
\hline VRQ/VRQ & R5 & Greatest risk & Greatest risk & & & \\
\hline \multicolumn{7}{|l|}{$\mathrm{ARH} / \mathrm{VRQ}$} \\
\hline ARQ/VRQ & & & & & $3(1.65)$ & $3(1.55)$ \\
\hline \multicolumn{7}{|l|}{ Allele } \\
\hline AHQ & & & & & $1(0.27)$ & $1(0.26)$ \\
\hline $\mathrm{ARH}$ & & & & & $8(2.2)$ & $8(2.06)$ \\
\hline ARQ & & & & $18(75)$ & $268(73.63)$ & $286(73.71)$ \\
\hline ARR & & Highly resistant & & $6(25)$ & $82(22.53)$ & $88(22.68)$ \\
\hline VRQ & & Highly sensitive & & & $5(1.37)$ & $5(1.29)$ \\
\hline
\end{tabular}

Frequencies are given in absolute values and as percentages (in brackets).

a These individuals form the rYM group.

b These individuals form the rYF group.

and 1128 individuals, totalling 1251 individuals. The YM and YF groups included, respectively, 11 and 182 individuals (totalling 193 individuals) that are those male and female individuals born in the last lambing season and selected for reproduction.

$\mathrm{PrP}$ genotype was considered in the groups of young individuals in order to account for additional losses of variation due to selection against susceptibility to scrapie. Breeding strategies with and without considering PrP genotype as the selective criterion were assessed and results were shown in a relative way with respect to the AM and AF groups.

When PrP genotypes are considered for selection the following criteria were taken into account: a) European rules aimed at increasing the frequency of the genotype ARR/ARR and elimination of the VRQ allele (European Commission, 2003); and b) the interest of the breeders association (ACOXA) in reducing the frequency of the ARQ allele, which has been shown to be associated with the highest risk of BSE in sheep (Baylis, 2002), thus reducing the risk to human health. Consequently, the additional losses of genetic variability due to selection for resistance to scrapie were assessed in a scenario in which only YM individuals with genotype ARR/ARR (risk group R1) and YF individuals with R1 to R3 risk group genotypes (which do not include either the VRQ allele or the ARQ/ARQ genotype) were expected to be used for reproduction. The assayed strategy coincides basically with that recently shown by Molina et al. (2006), consisting in genotyping rams and eliminating ARQ/ARQ and VRQ carriers, as the best strategy to improve the resistance and would cause minimal cost and loss of genetic variability.

Throughout the manuscript, the YF individuals with PrP genotype included in risk groups R1 to R3 and the R1 YM individuals will be considered 'resistant' and denoted as rYF and rYM, respectively. Results were compared with a breeding strategy in which no $\operatorname{PrP}$ genotype is used as the selective criterion, comparing the genetic variability retained by all the available YM and YF individuals or rYM and rYF individuals, always in reference to the AM and AF groups. A summary of the definition of the analysed breeding groups and the number of individuals forming them can be found in Table 2.

\subsection{Genealogical analyses}

Genealogical analyses on pedigree information were carried out using the program ENDOG (Gutiérrez and 
Table 2

Definition of the groups analysed in the present paper, number of individuals forming each analysed group at genealogical $(N)$ and molecular $(n)$ levels, and parameters characterising the genetic variability of the groups

\begin{tabular}{|c|c|c|c|c|c|c|c|c|c|c|}
\hline Breeding group & Abbreviation & $N$ & $n$ & $\mathrm{GD}^{\mathrm{a}}$ & $\mathrm{AR}$ & $c$ & $H_{\mathrm{e}}$ & $\mathrm{Mk}$ & $s$ & $A_{(6)}$ \\
\hline Adult reproductive females & $\mathrm{AF}$ & 1128 & 212 & 0.987 & 0.025 & 0.513 & 0.699 & 0.307 & 0.684 & 3.3 \\
\hline Female lambs selected for reproduction & YF & 182 & 33 & 0.982 & 0.036 & 0.517 & 0.648 & 0.346 & 0.724 & 3.1 \\
\hline Female lambs selected for reproduction with desirable PrP genotype & rYF & $71^{\mathrm{b}}$ & $71^{\mathrm{b}}$ & 0.981 & 0.039 & 0.524 & 0.631 & 0.343 & 0.724 & 3.1 \\
\hline Adult reproductive males & $\mathrm{AM}$ & 123 & 48 & 0.981 & 0.037 & 0.514 & 0.693 & 0.332 & 0.713 & 3.3 \\
\hline Male lambs selected for reproduction & YM & 11 & 11 & 0.982 & 0.036 & 0.519 & 0.672 & 0.317 & 0.731 & 3.3 \\
\hline Male lambs selected for reproduction with desirable PrP genotype & rYM & $2^{\mathrm{c}}$ & $2^{\mathrm{c}}$ & 0.970 & 0.060 & 0.533 & 0.537 & 0.342 & 0.703 & 3.1 \\
\hline Total population & & 1444 & 304 & 0.987 & 0.026 & 0.513 & 0.685 & 0.316 & 0.695 & 3.2 \\
\hline
\end{tabular}

The variables given are genealogical gene diversity (GD), average relatedness (AR) and genealogical self-coancestry $(c)$, expected heterozygosity $\left(H_{\mathrm{e}}\right)$, molecular mean kinship (Mk), molecular self-coancestry $(s)$, average number of alleles per locus $(A)$ rarefacted to 6 copies.

${ }^{\text {a }}$ Computed as $D=1-\bar{f}, \bar{f}$ being the average coancestry.

${ }^{\mathrm{b}}$ Notice that these 71 individuals are a part of the YF individuals.

${ }^{\mathrm{c}}$ Notice that these 2 individuals are a part of the YM individuals.

Goyache, 2005). The full coancestry ( $f$; Malècot, 1948) matrix of the Xalda pedigree, the individual coefficient of inbreeding $(F)$, defined as the probability that an individual has two identical alleles by descent, individual self-coancestry $\left(c_{i}\right.$, computed as $c_{i}=\frac{\left(1+F_{i}\right)}{2}$; Malècot, 1948), and the individual coefficient of average relatedness (AR) (Goyache et al. 2003; Gutiérrez et al. 2003), defined as the probability that an allele randomly chosen from the whole population in the pedigree belongs to the animal, were computed and further averaged per reference breeding group. The full between-individuals average-distance matrix (Caballero and Toro, 2002) was computed as $D_{a v}=\left[\left(c_{i}+c_{j}\right) / 2\right]-f_{i j}$, where $c_{i}$ and $c_{j}$ are the respective self-coancestries for individuals $i$ and $j$ and $f_{i j}$ the coancestry between individuals $i$ and $j$. Average distance is usually called kinship distance (Eding and Meuwissen, 2001). However, in order to avoid confusion, this term has been here used for the average distance computed on molecular information. Within- and between-reference breeding groups $f, c, \mathrm{AR}$ and $D_{a v}$ were simply computed by averaging the corresponding individual values for all the within- or between-group pairs of individuals. Finally, Nei's (1987) expected heterozygosity or gene diversity (GD) was also computed for each reference group as $\mathrm{GD}=1-\bar{f}$ (Caballero and Toro, 2000), where $\bar{f}$ is the average coancestry.

Notice that AR is twice the coancestry and that the inbreeding of an individual equals the coancestry of its parents. In consequence AR, self-coancestry (c), and GD are related in the following manner: $A R=$ $2(2 c-1)=2(1-\mathrm{GD})$. The higher diversity (GD) values the lower $c$ values. Inversely, the $c$ of the offspring of two individuals with average relatedness of AR will be $c=(1+(\mathrm{AR} / 2)) / 2$.

\subsection{Sampling and molecular analyses}

Blood samples were randomly obtained from a total of 304 reproductive (or selected for reproduction) Xalda individuals, kept in the 58 active flocks included in the ACOXA flockbook at the period of sampling. Samples were assigned to the corresponding reference breeding group according to the aforementioned criteria. The number of young individuals sampled was 44 (11 YM and $33 \mathrm{YF}$ ), whilst the sampled adult individuals summed to 260 (48 AM and $212 \mathrm{AF}$ ). Throughout the paper, the sampled individuals will be considered to be representative of the corresponding YM, YF, AM and AF groups.

Total DNA was isolated from blood samples following standard procedures (Sambrook et al., 1989). A set of 14 microsatellites (BM8125, BM6526, CP34, BM757, INRA006, BM6506, BM1818, FCB128, CSSM31, CSSM66, ILSTS011, McM53, RM006, ILSTS005) previously used in Álvarez et al. (2004, $2005 \mathrm{c}$ ) was analyzed in all the sampled individuals. The PCR products were labelled using a fluorescent method (Cy5 labeled primer) and genotyping was performed on an ALFexpressII automated sequencer (Amersham Biosciences, Barcelona). The microsatellite set used here was tested for linkage disequilibrium in Álvarez et al. (2004).

Analyses on molecular information were carried out using the program MolKin (Gutiérrez et al., 2005a). The following parameters were computed at the reference population level: expected heterozygosity $\left(H_{\mathrm{e}}\right.$; Nei, 1987) and average number of alleles per locus $(A)$ corrected using Hurlbert's rarefaction method (1971) as $A[g]=\sum_{i}\left[1-\prod_{k=0}^{g-1} \frac{N-N_{i}-k}{N-k}\right]$, where $g$ is the specified sampled size, $N$ the number of gene copies (alleles) 
examined in a given locus $(N>g)$, and $N_{i}$ the number of occurrences of the $i^{\text {th }}$ allele among the $N$ sampled gene copies to account for sample size. Notice that, in the case of no failure in genotyping, the maximum value of $N$ in a given population is twice the sampling size and the maximum value of $g$ is twice the number of individuals forming the population with the lowest sampling size.

The full molecular coancestry matrix between the genotyped individuals was computed. The molecular coancestry $(M)$ between two individuals $i$ and $j$ is the probability that two randomly sampled alleles from the same locus in two individuals are identical by state (Caballero and Toro, 2002). Molecular coancestry between two individuals $i$ and $j$ at a given locus can be computed using the following scoring rules (Caballero and Toro, 2002; Eding and Meuwissen, 2001): $M_{i j, l}=$ $1 / 4\left[I_{11}+I_{12}+I_{21}+I_{21}+I_{22}\right]$, where $I_{x y}$ is 1 when allele $x$ on locus $l$ in individual $i$ and allele $y$ on the same locus in individual $j$ are identical, and zero otherwise. Note that this value can take only four values: $0,1 / 4,1 / 2$ and 1 . The molecular coancestry between two individuals $i$ and $j\left(M_{i j}\right)$ can be obtained by simply averaging over $L$ analyzed loci as $M_{i j}=\frac{\sum_{l=1}^{L} M_{i, l},}{L}$. Moreover, the individual molecular self-coancestry (here denoted as $s_{i}$ ) was computed as $s_{i}=\frac{\left(1+F_{i}\right)}{2}$, where $F_{i}$ is not individual inbreeding, but homozygosity. Both $M$ and $s$ were averaged within- and between-reference groups when necessary. The between-individuals average-distance (here called kinship distance; $D_{k}$ ) matrix was computed as $D_{k}=\left[\left(s_{i}+s_{j}\right) / 2\right]-M_{i j}$ (Caballero and Toro, 2002), where $s_{i}$ is the molecular self-coancestry for individual $i$ and $M_{i j}$ the molecular coancestry between individuals $i$ and $j$. When necessary, these parameters were averaged over all the within- or between-group pairs of individuals.

Notice that $H_{\mathrm{e}}, M$ and $s$ are related in a similar way than that reported for their theoretically equivalent genealogical parameters: $M=(2 s-1)=\left(1-H_{\mathrm{e}}\right)$ and the $s$ of the offspring of two individuals with molecular coancestry of $M$ will be $s=(1+M) / 2$.

\section{Results}

Genotypic and allelic frequencies on the PrP gene for young individuals are given in Table 1. The ARQ allele frequency was roughly $75 \%$. The second most frequent allele was the favourable ARR (with a frequency of roughly 20\%), whilst the undesirable VRQ allele was present at a frequency of $1.3 \%$. From the PrP genotypes $55.4 \%(72.7 \%$ for the YM individuals) were ARQ/ ARQ, which is classified at the undesirable risk level
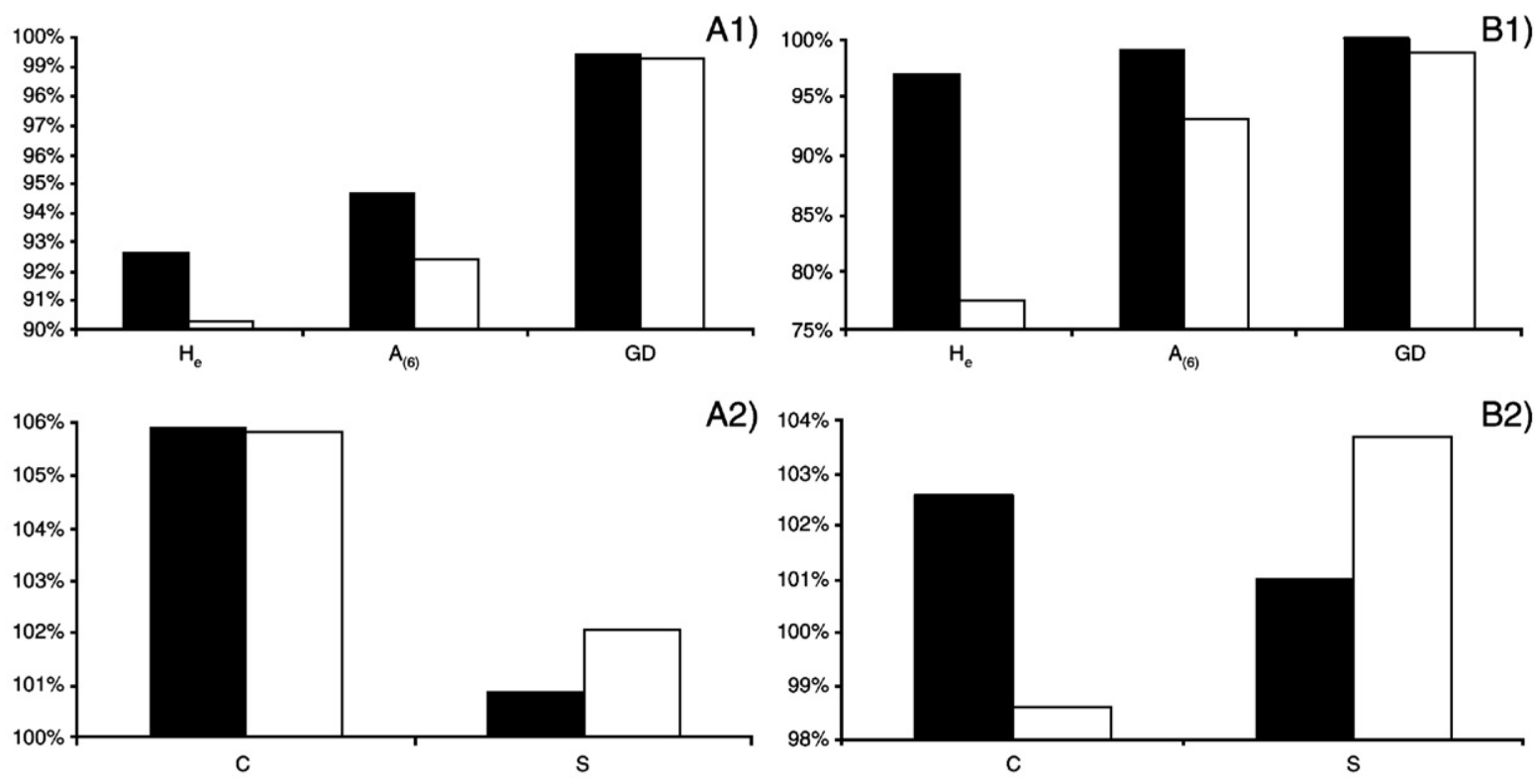

Fig. 1. Ratios (in percentage with respect to adult individuals) of the genetic variability retained by the young Xalda individuals selected for reproduction with (black bars) and without (open bars) using the $\mathrm{PrP}$ genotype as selective criterion. Plot A.1 gives the ratios for expected heterozygosity $\left(H_{\mathrm{e}}\right)$, rarefacted (to six copies) average number of alleles per locus $(A)$ and genealogical gene diversity (GD) corresponding to female individuals (ratio YF/AF, black bars; and ratio rYF/AF, open bars), whilst plot B.1 gives the same information for male individuals (ratio YM/AM, black bars; and ratio rYM/AM, open bars). Plot A.2 gives the ratios for expected molecular self-coancestry $(s)$ and genealogical self-coancestry $(c)$ corresponding to female individuals (ratio YF/AF, black bars; and ratio rYF/AF, open bars), whilst plot B.2 gives the same information for male individuals (ratio YM/AM, black bars; and ratio rYM/AM, open bars). 
R4. Moreover, the beneficial ARR/ARR genotype is only present in $5.7 \%$ of individuals $(18.2 \%$ of the males, comprising 2 young rams).

Genealogical and molecular parameters characterising the genetic variability in the reference groups and for the whole population are given in Table 2 . The expected heterozygosity, molecular mean kinship, molecular selfcoancestry and rarefacted (to 6 copies) average number of alleles per locus for the whole data set were 0.685 , $0.315,0.695$ and 3.2 , respectively. At the genealogical level, GD was 0.987 , mean AR was 0.026 and genealogical self-coancestry for the whole pedigree was 0.513 . Notice that maker-based identity values are always higher than those computed from pedigree information due to the pedigree-based parameters assume that founder alleles are unique and in the present population they are only identical by descent (Malècot, 1948) whilst in the case of molecular-based information two alleles can be identical by state (Caballero and Toro, 2002).

The main results given in Table 2 were graphically represented in Fig. 1 as percentage of the genetic variability retained by the resistant groups with respect to the corresponding AF and AM groups. Plot A.1 in Fig. 1 shows that $\mathrm{rYF}$ individuals retained most of the genetic variability computed for YF individuals. In turn, the YF group retained $92.64 \%, 94.69 \%$ and $99.48 \%$ of the values observed respectively for $H_{\mathrm{e}}, A_{(6)}$ and GD in the AF group. On the other hand, self-coancestry is slightly higher, respectively reaching ratios of $105.90 \%$ and $100.87 \%$ for $s$ and $c$ with respect to AF individuals (see plot A.2 in Fig. 1). Notice that self-coancestry is not diversity but an identity measure and then values above $100 \%$ characterise loss of diversity. The rYF individuals retained more than $97.5 \%$ of the variability computed for the YF group for $H_{\mathrm{e}}, A_{(6)}$ and GD, the molecular self-coancestry levels were basically the same and the ratio $\mathrm{rYF} / \mathrm{YF}$ for genealogical self-coancestry is only slightly higher (101.2\%).

The ratios corresponding to males followed a similar pattern. The percentages of variability retained by YM individuals are comparable to those reported above for the YF group. YM individuals retained $97.07 \%$, $99.07 \%$, and $100.07 \%$ of the variability computed in the AM group for $H_{\mathrm{e}}, A$ and GD, respectively (see plot B.1 in Fig. 1). Parameters $s$ and $c$ reached ratios of $105.90 \%$ and $100.87 \%$, respectively, with respect to AF individuals (see plot B.2 in Fig. 1). With respect to the YM group, rYM individuals retained 79.89\%, 94.12\%, and $98.75 \%$ of the variability computed respectively for $H_{\mathrm{e}}, A_{(6)}$ and GD. The corresponding ratios for $s$ and $c$ were respectively favourable at $96.1 \%$ and $102.1 \%$.
Table 3

Differentiation between the YF and YM groups (considering - rY the selective criterion of resistance to scrapie, or not) with respect to $\mathrm{AF}$ and AM individuals assessed through $D_{a v}$ and $D_{k}$ for genealogical and molecular information, respectively (see text)

\begin{tabular}{lll}
\hline & $D_{a v}$ & $D_{k}$ \\
\hline YF-AF & 0.499 & 0.373 \\
rYF-AF & 0.500 & 0.376 \\
YM-AM & 0.490 & 0.381 \\
rYM-AM & 0.476 & 0.552 \\
\hline
\end{tabular}

Differentiation assessed using $D_{a v}$ and $D_{k}$, among YM and YF groups with the corresponding AF and AM groups is given in Table 3. The differentiation of the YF and rYF individuals with respect to AF individuals is virtually the same regardless of the source of information used (molecular or genealogical). However, with regard to the males, rYM individuals present a lower differentiation with respect to the AM group than the total available group of YM animals. $D_{k}$ is more than $31 \%$ lower for rYM than for YM (0.552 vs 0.381$)$, whilst $D_{a v}$ is $2.9 \%$ lower for the same pairs (0.476 vs $0.490)$. This scenario is consistent with the higher values of AR and Mk found in rYM individuals with respect to YM rams (see Table 2), thus highlighting the higher genetic representation of the rYM genotypes in the whole group. In fact, the rYM individuals have higher values of genealogical and molecular coancestry with the AM group than the whole YM individuals thus reducing the differentiation assessed using kinshipbased genetic distances.

\section{Discussion}

The main goal of the present analysis is to assess the effect of selection for scrapie resistance on genetic variability in the rare Xalda sheep at the early stages of such a selective programme. To do so, we used a set of theoretically equivalent parameters at the genealogical and molecular level to obtain reliable conclusions from their analysis.

The predominant allele in the Xalda breed is ARQ, which has been shown to be also predominant in other Iberian coarse-wool sheep breeds (Álvarez et al., 2006; Gama et al., 2006; Álvarez et al., 2005a,b). The most frequent PrP genotype in the Xalda sheep is ARQ/ARQ, which is classified with an unacceptable risk to scrapie (R4). This scenario suggests the need to implement a breeding policy in order to increase genetic resistance to scrapie in the Xalda breed. However, frequencies of PrP genotypes with intermediate to low susceptibility to scrapie (from R1 to R3) comprise roughly a third of the 
population and the proportion of ARR/ARQ heterozygotes represents a quarter of the individuals, thus allowing the implementation of breeding strategies leading to gradual rather than drastic selection of ARR genotypes. Recently, Alfonso et al. (2006), in the nonrisk black-faced Latxa of Navarra dairy sheep breed, proposed a selection regime consisting in using only ARR/ARR reproductive males (or with a small proportion of ARR heterozygote rams), with no selection for PrP genotype in females. However this strategy cannot be explored in the Xalda sheep because this would not guarantee the elimination of the VRQ allele in the population. In this respect, since the presence of VRQ alleles in the population is limited, the elimination of VRQ-carrying animals would not result in extreme erosion of the genetic stock.

The present analysis was carried out assuming that the major cause of losses of genetic variability in the Xalda breed is the drift that occurs when a new group of reproductive individuals is selected. It can be argued that strict mating policies based on the minimisation of the average coancestry of the new reproductive individuals (Caballero and Toro, 2000) should be implemented in the breed in order to conserve its genetic variability. However, strict selective criteria based on individual coancestry coefficients are difficult to apply in the Xalda breed because selection depends on compliance with the breed standard, assignment of the individual to a founder line and the particular breeding situation of the flocks, among other factors. Consequently, most decisions aimed at avoiding losses of genetic diversity are taken at the flock level, computing average AR coefficients that may suggest the introduction of new, under-represented animals in a given flock (Goyache et al., 2003). Superimposed on this situation, the influence of the new requirements regarding selection against susceptibility to scrapie on the genetic variability of the Xalda breed must be assessed, first taking into account the drift due to selection.

In this respect, no losses of genetic variability at genealogical levels have been assessed for YF with respect to $\mathrm{AF}$ individuals, whilst losses at molecular levels are above $5 \%$. YM individuals also retain most of the genetic variability assessed in AM individuals. Selection against susceptibility to scrapie produces additional losses of more than $2 \%$ for $H_{\mathrm{e}}$ and $A$ when rYF individuals are considered. Regarding males, the situation becomes critical because of the scant number of available ARR/ARR young rams: $H_{\mathrm{e}}$ in $\mathrm{rYM}$ individuals is $20 \%$ lower than that of the whole group of young rams and $A$ is roughly $6 \%$ lower, thus limiting the long-term evolutionary potential of the population.
Moreover, the increase in self-coancestry with respect to the adult individual groups indicates that the diversity retained by young individuals is due more to betweenindividuals than to within-individuals diversity (Caballero and Toro, 2000, 2002). This general situation coincides with that observed for the parameter AR. This parameter and its molecular counterpart Mk provide information on the genetic representation of each individual in the population and, on average, can be used as an index to maintain the initial genetic stock, as well as to predict the long-term inbreeding (or homozygosity) of a population, thus suggesting modifications to management practice to conserve the genetic makeup of a population (Gutiérrez et al, 2003; Goyache et al., 2003; Gutiérrez et al., 2005a,b). In our study, both AR and Mk for rYM individuals largely exceed those for the YM group.

In order to compare the expected genetic variability of the offspring produced by crossing males and females of each reference group, expected heterozygosity $\left(H_{\mathrm{e}}\right)$, genealogical gene diversity (GD) and increases in inbreeding $[\Delta(1-\mathrm{GD})]$ and homozygosity $\left[\Delta\left(1-H_{\mathrm{e}}\right)\right]$ were respectively computed from average allelic frequencies and genealogical coancestry values (Table 4). The increase in inbreeding and homozygosity for the $\mathrm{rYF} \times \mathrm{rYM}$ offspring is, respectively, four and two times higher than that obtained for the $\mathrm{YF} \times \mathrm{YM}$ offspring, thus pointing out a serious concern for the conservation program of the Xalda sheep breed. If selection aimed at increasing genetic resistance to scrapie needs to be applied, the maintenance of the genetic background from the founder population will need unbalanced contributions from the individuals selected for reproduction to the genetic background of the population, thus suggesting the implementation of a mating policy aimed at obtaining homozygous ARR/ARR rams from heterozygous ARR/ARQ individuals.

In general, sets of genealogical and molecular parameters computed here give similar information on

Table 4

Expected values of genealogical gene diversity (GD) and expected heterozygosity $\left(H_{\mathrm{e}}\right)$ computed for the progeny produced by crossing $\mathrm{AF}$ with $\mathrm{AM}$ individuals $(\mathrm{AF} \times \mathrm{AM}), \mathrm{YF}$ with $\mathrm{YM}$ individuals $(\mathrm{YF} \times \mathrm{YM})$ and $\mathrm{rYF}$ with $\mathrm{rYM}$ individuals $(\mathrm{rYF} \times \mathrm{rYM})$

\begin{tabular}{lllll}
\hline & GD & $H_{\mathrm{e}}$ & $\Delta(1-\mathrm{GD})$ & $\Delta\left(1-H_{\mathrm{e}}\right)$ \\
\hline $\mathrm{AF} \times \mathrm{AM}$ & 0.982 & 0.676 & & \\
$\mathrm{YF} \times \mathrm{YM}$ & 0.971 & 0.632 & 0.011 & 0.065 \\
$\mathrm{rYF} \times \mathrm{rYM}$ & 0.940 & 0.586 & 0.043 & 0.133 \\
\hline
\end{tabular}

Additionally the increase in inbreeding $[\Delta(1-\mathrm{GD})]$ and homozygosity $\left[\Delta\left(1-H_{\mathrm{e}}\right)\right]$ with respect adult individuals are given for the $\mathrm{YF} \times \mathrm{YM}$ and $\mathrm{rYF} \times \mathrm{rYM}$ crosses. 
the direction of the losses of genetic variability due to selective processes. However, relationship between genealogical parameters and their molecular counterparts is not straightforward and losses of variability assessed at the molecular level are higher. When sufficient pedigree information is available the use of molecular information in conservation programmes is not always recommended (Fernández et al., 2005). However, when genealogies are shallow, as usually happens at the beginning of a conservation program, the use of molecular parameters can be justified in order to accurately asses some scenarios of conservation.

\section{Conclusions}

Major losses of genetic variability are due to selection of new reproductive individuals. The implementation of strict selection strategies aimed at reducing susceptibility to scrapie in rare sheep populations affects conservation programs. As assessed here using genealogical and molecular parameters, the additional loss of variation due to selection for scrapie resistance is not dramatic for females. However, when the available number of rams resistant to scrapie is low, diversity levels of a rare sheep breed may become critical (Molina et al., 2006) affecting the long-term evolutionary potential of the population. A mating policy focused on obtaining resistant individuals from ARR heterozygote parents should be carefully implemented before the beginning of such a selective programme so as to avoid problems in current conservation programs in rare sheep breeds. The combined use of genealogical and molecular information in this scenario of conservation can be recommended. The implementation of a germplasm bank in order to manage the risks of novel ovine PrP polymorphisms and losses of genetic potential is also recommendable (Roughsedge et al., 2006).

\section{Acknowledgments}

This work was partially funded by grants from MECINIA, No. RZ2004-00007-C02 and from the Regional Government of the Principado de Asturias No. PCREC04-27. The authors are indebted to the Xalda Breeders Association (ACOXA; http://www.xalda.com/) for its kind collaboration.

\section{References}

Alfonso, L., Parada, A., Legarra, A., Ugarte, E., Arana, A., 2006. Effects on genetic variability of selection against scrapie sensitivity in the Latxa black-faced sheep. Genet. Sel. Evol. 38, 495-511.
Álvarez, I., Royo, L.J., Fernández, I., Gutiérrez, J.P., Gómez, E., Goyache, F., 2004. Genetic relationships and admixture between six Northern Spain sheep breeds assessed through microsatellites. J. Anim. Sci. 82, 2246-2252.

Álvarez, L., Arranz, A.A., San Primitivo, F., 2005a. Identification of mew leucine haplotype (ALQ) at codon 154 in the ovine prion protein gene in Spanish sheep. J. Anim. Sci. 84, 259-265.

Álvarez, I., Fernández, I., Goyache, F., Arranz, J.J., Gutiérrez, J.P., Gómez, E., Royo, L.J., 2005b. Frecuencais alélicas y genotípicas del gen PRP en la raza ovina Xalda de Asturias en relación con el color de la capa. ITEA 26 Vol. Extra I, pp. 75-77.

Álvarez, I., Gutiérrez, J.P., Royo, L.J., Fernández, I., Gómez, E., Arranz, J.J., Goyache, F., 2005c. Testing the usefulness of the molecular coancestry information to assess genetic relationships in livestock using a set of Spanish sheep breeds. J. Anim. Sci. 83, 737-744.

Álvarez, L., Gutiérrez-Gil, B., San Primitivo, F., de la Fuente, L.F., Arranz, J.J., 2006. Influence of prion protein genotypes on milk production traits in Spanish Churra sheep. J. Dairy Sci. 89, 1784-1791.

Álvarez Sevilla, A., Gutiérrez, J.P., Fernández, I., Royo, L.J., Álvarez, I., Gómez, E., Goyache, F., 2004. Conservación de la oveja Xalda de Asturias. AGRI 34, 41-49.

Baylis, M., 2002. The BSE-susceptible proportion of UK sheep. Vet. Rec. 151, 481-482.

Brandsma, J.H., Visscher, L.L.G., 2004. Association between PrP genotypes and littersize and 135 days weight in Texel sheep. Livest. Prod. Sci. 85, 59-64.

Caballero, A., Toro, M.A., 2000. Interrelations between effective population size and other pedigree tools for the management of conserved populations. Genet. Res. Camb. 75, 331-343.

Caballero, A., Toro, M.A., 2002. Analysis of genetic diversity for the management of conserved subdivided populations. Conserv. Genet. 3, 289-299.

De Vries, F., Hamann, H., Drögemüller, C., Ganter, M., Distl, O., 2005. Analysis of associations between the prion protein genotypes and production traits in East Friesian milk sheep. J. Dairy Sci. 88, 392-398.

Elsen, J.M., Amigues, Y., Schelcher, F., Ducrocq, V., Andreoletti, O., Eychenne, F., Tien Khang, J.V., Poivey, J.P., Lantier, F., Laplanche, J.P., 1999. Genetic susceptibility and transmission factors in scrapie: detailed analysis of an epidemic in a closed flock of Romanov. Arch. Virol. 144, 431-445.

Eding, H., Meuwissen, T.H.E., 2001. Marker-based estimates of between and within population kinships for the conservation of genetic diversity. J. Anim. Breed. Genet. 118, 141-159.

European Commission, 2003. Commission Decision of 13 February 2003 Laying Down Minimum Requirements for the Establishment of Breeding Programmes for Resistance to Transmissible Spongiform Encephalopathies in Sheep (2003/100/EC).

Fernández, J., Villanueva, B., Pong-Wong, R., Toro, M.A., 2005. Efficiency of the use of pedigree and molecular marker information in conservation programs. Genetics 170, 1313-1321.

Gama, L.T., Carolino, M.I., Santos-Silva, M.F., Pimenta, J.A., Costa, M.S., 2006. Prion protein polymorphisms and breeding strategies in Portuguese breeds of sheep. Livest. Sci. 99, 175-184.

Goyache, F., Gutiérrez, J.P., Fernández, I., Gómez, E., Álvarez, I., Díez, J., Royo, L.J., 2003. Monitoring pedigree information to conserve the genetic variability in endangered populations: the Xalda sheep breed of Asturias as an example. J. Anim. Breed. Genet. 120, 95-103.

Gutiérrez, J.P., Goyache, F., 2005. A note on ENDOG: a computer program for analysing pedigree information. J. Anim. Breed. Genet. 122, 357-360. 
Gutiérrez, J.P., Altarriba, J., Díaz, C., Quintanilla, R., Cañón, J., Piedrafita, J., 2003. Pedigree analysis of eight Spanish beef cattle breeds. Genet. Sel. Evol. 35, 43-63.

Gutiérrez, J.P., Royo, L.J., Álvarez, I., Goyache, F., 2005a. MolKin v2.0: a computer program for genetic analysis of populations using molecular coancestry information. J. Heredity 96, 718-721.

Gutiérrez, J.P., Marmí, J., Goyache, F., Jordana, J., 2005b. Pedigree information reveals moderate to high levels of inbreeding and a population genetic structure in the Catalonian donkey breed. J. Anim. Breed. Genet. 122, 378-386.

Hunter, N., 1997. Molecular biology and genetics of scrapie in sheep. In: Piper, L., Ruvinsky, A. (Eds.), The Genetics of Sheep. CAB International.

Hurlbert, S.H., 1971. The non concept of species diversity: a critique and alternative parameters. Ecology 52, 577-586.

Malécot, G., 1948. Les Mathématiques de l'Hérédité. Masson et Cie, Paris, France.

Molina, A., Juárez, M., Rodero, A., 2006. Merino sheep breed's genetic resistance to scrapie: genetic structure and comparison of five eradication strategies. Prev. Vet. Med. 75, 239-250.

Nei, M., 1987. Molecular Evolutionary Genetics. Columbia University Press, New York. University Press, New York.

O’Doherty, E., Healy, A., Aherne, M., Hanrahan, J.P., Weavers, E., Doherty, M., Roche, J.F., Gunn, M., Sweeney, T., 2002. Prion protein $(\mathrm{PrP})$ gene polymorphisms associated with natural scrapie cases and their flock-mates in Ireland. Res. Vet. Sci. 73, 243-250.
Prusiner, S.B., 1998. Prions. Proc. Natl. Acad. Sci. U. S. A. 95, 13363-13383.

Roughsedge, T., Villanueva, B., Woolliams, J.A., 2006. Determining the relationship between restorative potential and size of a gene bank to alleviate the risks inherent in a scrapie eradication breeding programme. Livest. Sci. 100, 231-241.

Royo, L.J., Álvarez, I., Gutiérrez, J.P., Fernández, I., Goyache, F., 2007. Genetic variability in the endangered Asturcón pony assessed using genealogical and molecular information. Livest. Sci. 107. doi:10.1016/j.livsci.2006.09.010.

Sambrook, J., Fritsch, E.F., Maniatis, T., 1989. Molecular Cloning: A Laboratory Manual. Cold Spring Harbor Laboratory Press, Cold Spring Harbor, USA.

Toro, M.A., Barragán, C., Óvilo, C., Rodrigáñez, J., Rodríguez, C., Silió, L., 2002. Estimation of coancestry in Iberian pigs using molecular markers. Conserv. Genet. 3, 309-320.

Toro, M.A., Barragán, C., Óvilo, C., 2003. Estimation of genetic variability of the founder population in a conservation scheme using microsatellites. Anim. Genet. 34, 226-228.

Windig, J.J., Eding, H., Moll, L., Kaal, L., 2004. Effects on inbreeding of different strategies aimed at eliminating scrapie sensitivity alleles in rare sheep breeds in The Netherlands. Anim. Sci. 79, 11-20.

Vitezica, Z.G., Moreno, C.R., Bouix, J., Barillet, F., Perret, G., Elsen, J.M., 2005. A study on associations between PrP genotypes and meat traits in French sheep breeds. Anim. Sci. 81, 325-330. 